\title{
Döviz Kuru, VIX Korku Endeksi ve Yabancı Portföy Yatırımları Etkileşimi
}

\author{
Müberra GÜNGÖR* \\ *Nuh Naci Yazgan Üniversitesi, İktisadi İdari Bilimler Fakültesi, İşletme Bölümü, Kayseri, Türkiye, (0000-0002-6592-3450), mgungor@nny.edu.tr \\ (International Conference on Design, Research and Development (RDCONF) 2021 - 15-18 December 2021)
}

(DOI: 10.31590/ejosat.1044711)

\begin{abstract}
ATIF/REFERENCE: Güngör, M., (2021). Döviz Kuru, VIX Korku Endeksi ve Yabancı Portföy Yatrımları Etkileşimi. Avrupa Bilim ve Teknoloji Dergisi, (32), 1034-1042.
\end{abstract}

Öz

Bu çalışmanın amacı VIX Korku Endeksi (Volatilite Endeksi) ile döviz kurunun, portföy yatırımları üzerinde etkili olup olmadığını belirlemektir. Bu doğrultuda Ocak 2009 -Ağustos 2021 dönemi aylık verileri kullanılarak değişkenler arasındaki eşbütünleşme ilişkisinin tespiti için ARDL Sınır testi yöntemi kullanılmıştır. ARDL Sınır Testi sonuçlarına göre portföy yatırımları, döviz kuru ve VIX korku endeksi arasında uzun dönemli bir ilişki bulunmakla birlikte, modellerdeki uzun dönem katsayı tahmin sonuçlarına bakıldığında sadece döviz kurunun portföy yatırımları üzerinde anlamlı bir etkisi bulunmuştur. Hata düzeltme modeli sonuçlarına göre ise kısa dönemde döviz kurunun portföy yatırımları üzerinde negatif ve anlamlı, VIX korku endeksi değişkeninin ise portföy yatırımları üzerinde pozitif ve anlamlı bir etkisinin olduğu sonucuna ulaşılmıştır.

Anahtar Kelimeler: VIX Korku Endeksi, Portföy Yatırımları, Döviz Kuru.

\section{The Interaction of the Exchange Rate, the VIX Fear Index and Foreign Portfolio Investments}

\begin{abstract}
The purpose of this study is to determine whether the VIX Fear Index (Volatility Index) and the exchange rate have an effect on portfolio investments. In this direction, ARDL Bounds test method was used to determine the cointegration relationship between the variables by using monthly data for the period January 2009 - August 2021. According to the results of the ARDL Boundary Test, there is a long-term relationship between portfolio investments, the exchange rate and the VIX fear index, but when looking at the results of long-term coefficient estimates in models, only the exchange rate had a significant effect on portfolio investments. According to the results of the error correction model, it was concluded that the exchange rate had a negative and significant effect on portfolio investments in the short term, and the VIX fear index variable had a positive and significant effect on portfolio investments.
\end{abstract}

Keywords: VIX Fear Index, Portfolio Investments, Exchange Rate, ARDL Bound Test

* Sorumlu Yazar: mgungor@nny.edu.tr 


\section{Giriş}

Küreselleşmenin gelişmesiyle birlikte dünya ekonomisindeki tasarruf ve yatırımların ülkeler arasında etkin dağılımının gerçekleşmesi mümkün olabilmektedir. Küreselleşme öncesinde fazla önemsenmeyen doğrudan yabancı sermaye ya da portföy yatırımları bugün ister gelişmiş ister gelişmemiş olsun bütün ülkelerin ilgi odağ (Afşar, 2004: 85). Nakit, hisse senedi ve tahvil gibi finansal varlıkların karını en yüksek düzeye çıkarmak amacıyla uluslararası sınırlara aktarılmasıyla oluşan yabancı portföy yatırımları (FPI); yatırım yapan tarafın yapılan yatırımlar üzerinde herhangi bir kontrol yetkisinin olmadığı yabancı ülke finansal varlıklarının satın alınması anlamına gelmekte ve çeşitli şekillerde gerçekleşebilmektedir (Ogbonna, Calistus ve Clement, 2019: 1). Böylelikle yabancı portföy yatırımları, doğrudan yabancı yatırımlar gibi, beklenen getirilerin düşük olduğu sermaye zengini ülkelerden, beklenen getirilerin yüksek olduğu sermaye kıtlığı ülkelerine finansal kaynakların akmasını ve daha iyi kaynak tahsisini sağlayarak finansal piyasalara daha güvenilir, şeffaf ve sağlıklı bir yapı kazandırması bakımından önemli bir fon kaynağı olarak görülmektedir (Pal, 2011: 121123; Elekwa, Aniebo ve Ogu, 2016; Pazarlığlu ve Gülay, 2007: 209; Kaya ve Öndeş, 1997: 21). Bununla birlikte yatırımcılar, finansal piyasalarda meydana gelebilecek olumsuz gelişmeler karşısında kendilerini korumayı ve risklerden olabildiğince en az zararla etkilenmeyi amaçlasalar da finansal piyasalar arasında entegrasyonun artmasıyla, volatilite yayılımının (Kök ve Nazlığlu, 2020, 246) diğer piyasalara yansıması kaçınılmaz olabilmektedir. $\mathrm{Bu}$ doğrultuda "yatırımcılar; yaptıkları yatırımlardan yüksek getiri sağlamak için volatilite yayılma etkilerini izlemek suretiyle karşılaşabilecekleri olası genel risklerden kaçınabilmek amacıyla uluslararası finansal piyasaları izleyebilecek, piyasa hareketlerinin seyrini öngörebilecek ve yatırımları yönlendirebilecek bir takım yönlendirici göstergelere ihtiyaç duymaktadırlar. Temel gösterge olarak kabul edilen volatilite ise finansın en önemli kavramıdır." Ilk kez Chicago Opsiyon Borsası'nın 1993'te oluşturduğu volatilite endeksi (VIX); esasen S\&P 500 endeksine dayanmaktadır. Tam adı "Chicago Board Options Exchange Volatility Index" olan bu endeks finansal piyasalarda genellikle VIX endeksi olarak bilinmektedir. Finansal piyasaların belirsizliği ve getirilerdeki dalgalanma, bu belirsizlikten korunma ihtiyacını doğurmuş ve çeşitli enstrümanların oluşturulması yoluna gidilmiştir. $\mathrm{Bu}$ doğrultuda volatilite endeksleri oluşturulmaya başlanmış ve günümüz finansal piyasalarında ve dünya genelinde takip edilen önemli bir gösterge haline gelmiştir (Telçekelen vd., 2019: 205; Bektaş ve Babuşçu, 2019: 99). Volatilite endeksleri, ilgili endekste yer alan hisse senetlerinin alım ve satım opsiyonlarının zımni volatiliteleri kullanılarak hesaplanmaktadır. Endesk değerinin \%30'dan yüksek olması piyasadaki yatırımcıların geleceğe dair olumsuz beklenti içinde olduklarını, \%20'nin altında olması ise yatırımcıların piyasaya ilişkin endişe düzeyinin azaldığını ve risk algısının azaldığını göstermektedir (Kaya vd, 2014: 2; Bektaş ve Babuşçu, 2019: 99)

Çalışmanın bir diğer değişkeni ise döviz kurudur. Tasarruflarını artırmak ve yatırımlarını gerçekleştirmek isteyen gelişmekte olan ülkelerin yabancı sermayeden beklentisi ekonomik kalkınmalarını sağlamak olsa da, yaşanılan deneyimler zaman zaman bu olumlu beklentilerin gerçekleşmediğini gösterebilmektedir. Ülke parasının reel olarak değerinin artması ya da azalması anlamına gelen reel kurdaki oynaklıklar ülke ekonomilerinin rekabet gücünün yanı sıra dış ticaret yapısını ve yabancı sermaye akımlarını da doğrudan etkilemektedir (Aktaş, 2010: 124). Döviz kuru belirsizliğinin ortadan kalkmayacağına dair öngörüler geleceğe yönelik endişeleri artırarak yabancı yatırımcıların yatırım yapma konusunda çekimser kalmasına neden olabilmektedir. (Mann, 2002: 131; Edwards, 1988;). Yabancı yatırımları çekebilmek amacıyla çeşitli politikalar ya da teşvikler sunulsa da söz konusu yatırımların ülkeye gelmesini sağlayan en önemli faktörlerden biri istikralı bir döviz kuru olmaktadır (Sezer, 2020: 838).

VIX endeksi ve döviz kurları ile yabancı portföy yatırımları arasındaki etkileşimin ele alındığı bu çalışmanın temel amacı; Türkiye'de döviz kurları ile VIX korku endeksinin yabancı portföy yatırımları üzerindeki kısa ve uzun dönemli etkilerini Autoregressive Distributed Lag-ARDL modelinin kullanılarak tahmin edilmesidir. Böylece yatırımcılar ve politika yapıcılarına katkı sağlaması düşünülmektedir. Literatüre bakıldığında VIX korku endeksi ya da döviz kurunun çeşitli ekonomik göstergeler kullanılarak yapıldığı çalışmalara rastlanılmasına rağmen VIX korku endeksinin ve döviz kurunun portföy yatırımları ile ilişkisini ele alan çalışmaların sınırlı olduğu görülmüştür.

\section{Literatür}

Literatürede farklı dönemlere farklı değişkenler VIX endeksi, döviz kuru ya da benzer göstergeler kullanılarak söz konusu değişkenler arasındaki ilişkiyi ele alan çalışmalar mevcuttur.

Akdağ (2019), "VIX korku endeksi ile BIST 100 endeksi, döviz kuru endeksleri, gösterge tahvil faiz oranları, satın alma yöneticileri endeksi (PMI), reel kesim güven endeksi (RKGE), sanayi üretim endeksi (SÜE), tüketici güven endeksi (TGE) ve risk iştahı endeksi (RISSE)" değişkenleri arasındaki ilişkiyi ele aldığı çalışmada verileri Granger Nedensellik ve Johansen Eşbütünleşme analiz yöntemleri ile analiz etmiş, VIX'in gösterge tahvil faiz oranları dışındaki değişkenleri etkilediğini fakat bu etkinin geçici olduğunu sonucunu bulmuştur.

Kiracı (2019), "BİST Turizm Endeksi ile dolar kuru, dolar endeksi ve petrol fiyatları" arasındaki nedensellik ilişkisini konu alan çalışmasında 01.01.2003 - 24.07.2018 dönemi günlük verilerini Granger nedensellik ve Hatemi-J (2012) asimetrik nedensellik analizi yöntemleriyle analiz etmiş ve her iki yöntemle de değişkenler arasında nedensellik ilişkisinin bulunduğunu tespit etmişlerdir.

Sarıtaş ve Nazlığlu (2019), "VIX korku endeksi ile BİST 100 ve döviz kurları" arasındaki etkileşimi ele aldıkları çalışmalarında 02.01.2009 - 12.11.2018 tarihleri arasındaki günlük verileri; VAR modeli, varyans ayrıştırması ve Granger nedensellik yöntemleri ile analiz etmişlerdir. Yapılan analizler etki ve tepki fonksiyonları, korku endeksi şokunun BIST100 üzerinde negatif, dolar kuru üzerinde pozitif etkisi olduğunu göstermiştir. Varyans ayrıştırması analizi, VIX'in dolar kurunun öngörü hata varyansını açıklama oranının BIST'e kıyasla daha büyük olduğunu ortaya koymuştur. Nedensellik analizine göre ise, VIX'ten BIST100'e ve dolar kuruna doğru bir nedenselliğin olduğu bulunmuştur.

Öner vd. (2018), "gelişmekte olan 10 ülkenin hisse senetleri endeksleri ile VIX endeksi” arasındaki kısa ve uzun dönemli 
ilişkiyi araştırdıkları çalışmalarında söz konusu ülkelerin endeks verilerini kullanarak 23 Ekim 2006 - 10 Mayıs 2017 tarihleri arasındaki günlük verileriyle Engel-Granger Eş-bütünleşme ve Granger Nedensellik Testini uygulamışlar, Arjantin hariç diğer tüm ülkelerin endeksleri ile kısa ve uzun dönemli ilişki bulmuşlardır.

Çağlar Bektaş ve Babuşcu (2019), çalışmalarında "VIX korku endeksi büyüme, döviz kurları ve CDS primi” arasındaki etkileşimi incelemeyi amaçlamışlardır. $\mathrm{Bu}$ doğrultuda Ocak 2008 - Aralık 2018 dönemleri arasındaki verilerle Granger Nedensellik analizi uygulamışlardır. Çalışma sonucunda volatilite endeksinin sanayi üretim endeksinin nedeni olduğu tespit edilmekle birlikte diğer değişkenler arasında bir nedensellik ilişkisi bulunamamıştır.

Gülhan (2020), Türkiye'de altın fiyatının belirleyicilerini incelemek amaciyla "altın fiyatları, petrol fiyatları, BIST100 Endeksi, döviz kuru (ABD Doları), VIX Endeksi” nin 20152019 yılları arası haftalık verileriyle Granger nedensellik analizi ve VAR analizleri uygulamıştır. Yapılan analizler neticesinde sadece petrol fiyatları ile BİST100 değişkenlerinin birbirlerini karşılıklı olarak etkilediği, VIX Endeksi dışındaki değişkenlerin ise altın fiyatlarının belirleyicileri olduğu tespit edilmiştir.

Kök ve Nazlığlu (2020), "BIST100 Endeksi, ABD Doları ve VIX Endeksi”nin 02 Eylül 2009- 12 Aralık 2018 dönemi günlük verilerini kullanarak, hisse senedi piyasaları ve döviz kurları arasındaki nedensel ilişkiyi ve piyasalardaki oynaklığı asimetrik nedensellik yöntemi ile incelemişlerdir. Analiz sonucunda; VIX'te görülen yüksek riskin $\mathrm{ABD}$ doları ve BIST100 volatilitesini etkilediği, ayrıca ABD dolarındaki pozitif volatilitenin BIST100'ün pozitif ve negatif volatilitesini etkilediği yönünde bir sonuca varılmıştır.

Ercan ve Demirbaş (2021), çalışmalarında dolar endeksininin VIX korku endeksi üzerindeki etkisini incelemeyi amaçlamışlardır. 01.01.2010- 31.03.2020 tarihleri arasındaki günlük veriler kullanılarak önce ARDL sınır testi uygulayarak değişkenler arasında uzun dönemli ilişki olduğu anlaşılmıştır. Daha sonra Granger nedensellik analizi ile VIX Korku endeksinin dolar endeksinin nedeni olduğu tespit edilmiştir.

Arbatlı (2011), 46 gelişmekte olan ülkenin 1990-2009 yılları arasını kapsayan verileri yardımıya bu ülke ekonomilerine yönelik doğrudan sermaye yatırımlarını etkileyen faktörleri araştırmış ve belirsizliğe neden olan değişkenlerin söz konusu yatırımlar üzerinde önemli bir etkisi olduğu sonucuna varmıştır. Belirsizliğin VIX endeksi ile temsil edildiği çalışmada VIX endeksi ile doğrudan yabancı yatırımlar arasındaki koşulsuz korelasyon düşük bulunsa da 2006 yılından sonra VIX endeksi ile doğrudan yabancı sermaye yatırımları arasında ters yönlü etkileşimin olduğu belirlenmiştir.

Bagchi (2012), çalışmasında Hindistan VIX endeksi ile hisse senedi değerleme ölçütü olarak 6 adet portföy arasındaki ilişkiyi inceleyerek, 2007-2009 yılları arasındaki günlük verileri kullanmıştır. Portföyler arasındaki ilişkiyi çoklu regresyon yöntemiyle analiz ederek Hindistan VIX endeksi ile oluşturduğu portföyler arasında anlamlı ve pozitif bir ilişki olduğu sonucuna varmıştır.

Kliger ve Kudryavtsev (2013), yapmış oldukları çalışmada VIX endeksinin, yatırımcıların yatırım kararlarında analistlerin tavsiyelerine herhangi bir etkisinin olup olmadığını belirlemek istemişler ve 2002-2011 yılları arasına ait günlük verileri ele almışlardır. Çalışma sonucunda yatrımcılar açısından VIX'in gelecekteki ekonomik koşulların bir göstergesi olarak görüldüğü ve bu nedenle VIX endeksindeki artış ya da azalışların hisse senedi fiyat önerilerine yansıdığı ortaya konulmuştur.

Basher ve Sadorsky (2016), çalışmalarında Türkiye de dahil 23 gelişmekte olan ülkenin "hisse senedi, petrol, altın ve tahvil fiyatları ile VIX endeksi”" arasındaki ilişkiyi ele almış 04.01 2000 - 31.07.2014 tarihleri arasındaki günlük verileri kullanmışlardır. "DCC, ADCC ve GO-GARCH" yöntemleri kullanılarak söz konusu ülkelerin pay piyasaları ile petrol fiyatları arasında pozitif kaldıraç etkisi olduğu, gelişmekte olan ülke hisse senetlerine yönelik riskten korunma işleminin en uygun petrol ile yapılabileceği sonucuna ulaşmışlardır. GoGarch'tan hesaplanan hedge oranlarına bakıldığında ise borsa fiyatlarının yükselmesi durumunda en iyi korunma yönteminin altına yatırım yapılarak sağlanacağı sonucuna ulaşmışlardır.

Emna ve Myriam (2017), çalışmalarında Euro bölgesi ülkelerine yönelik "volatilite endeksleri ile hisse senedi getirileri” arasındaki ilişkiyi ele almışlardır. İsviçre, İngiltere, Almanya ve Fransa'nın 2010- 2015 yılları arasındaki yıllık verilerini kullandıkları çalışma sonucunda İsviçre hisse senedi getirileri ile VIX endeksinin karşılıklı birbirini etkilediği sonucuna ulaşmışlardır. Ayrıca Fransa hisse senedi endeksindeki artış ya da azalışların VIX endeksi üzerinde kaldıraç etkisi olduğuna işaret etmişlerdir. Almanya' da da VIX endeksi ile hisse senedi getirileri arasında bir ilişki bulunurken, İngiltere için benzer bir ilişki bulunamadığı görülmüştür.

Neffelli ve Resta (2018), çalışmalarında Ocak 2007 - Şubat 2018 dönemleri arasındaki "VIX endeksi ile ABD sermaye piyasası ve BRIC ülkeleri sermaye piyasaları" arasındaki ilişkiyi ele almışlardır. "Genelleştirilmiş Momentler” yöntemini (GMM) kullandıkları çalışmalarından elde edilen sonuçlara göre VIX endeksi 2008 krizi döneminde artmış ve yatırımcıların vermiş oldukları tepkiler analiz sonuçlarını etkilemiştir. Ayrıca Brezilya, Çin, Hindistan ve Rusya'da VIX endeksinin ülkelerin sermaye piyasaları üzerinde etkili olduğu sonucuna ulaşmışlardır.

Sadeghzadeh (2018), 2004:M01- 2018:M04 dönemi verilerini aldığı çalışmasında BIST 100 endeksini etkileyen psikolojik faktörleri ele almış; BIST 100 kapanış fiyatları, ABD VIX endeksi ve Türkiye Tüketici Güven endeksi verilerini kullanılmıştır. Değişkenler arasındaki nedenselliği Granger nedensellik analizi ile ölçerek BIST 100 endeksinden tüketici güven endeksine doğru tek yönlü nedensellik ilişkisinin, VIX endeksinden de tüketici güven endeksine tek yönlü nedensellik ilişkisinin olduğu sonucuna ulaşmışlardır.

Literatürde yabancı portföy yatırımları ile çeşitli ekonomik göstergeleri ele alan bazı çalışmalara da aşağıda yer verilmiştir.

Agarwal (1997), 6 gelişmekte olan Asya ülkesinde "yabanc1 portföy yatırımlarının belirleyicilerini" ve "ulusal ekonomiler üzerine etkilerini” araştırdıkları çalışmada enflasyon oranı, döviz kuru, ekonomik faaliyet endeksi ve yerli sermaye piyasasının yabancı portföy yatırımlarının belirleyicileri olduğunu, yabancı portföy yatırımlarının ise ekonomik faaliyet endeksi ve enflasyon oranını etkilediği sonucuna ulaşmışlardır.

Egly vd. (2010), Ocak 1977-2007 Aralık dönemlerindeki aylık verilerle, ülkeye giren yabancı portföy yatırımları ile yatırımcının riskten kaçınma tepkileri ve ABD borsası arasındaki 
ilişkileri analiz etmişlerdir. VAR analiziyle yürütülen çalışmalarında yabancı portföy yatırımlarında hisse senetlerine yönelik riskten kaçınma tepkisi görülmezken, tahvillere yönelik riskten kaçınma tepkisi görülmüştür.

Kodongo ve Ojah (2012), 1997-2009 döneminde aylık verilerle, Mısır, Fas, Nijerya ve Güney Afrika bazında yabancı döviz kuru ile yabancı portföy yatırımları arasındaki ilişkiyi incelemiş, söz konusu yatırımların Afrika'da süreklilik göstermediği ancak döviz kuru ile arasında bir etkileşimin bulunduğunu tespit etmişlerdir.

Garg ve Dua (2014), 1995-2012 döneminde aylık verilerle Hindistan'daki yabancı portföy yatırımlarına uzun dönemli etki eden makro ekonomik göstergeleri belirlemek istemişşlerdir. Çalışma sonucunda kur riskinin ve piyasa getirilerinin yabancı portföy yatırımlarını negatif yönde etkilediği, "riski çeşitlendirme"nin yatırım kararlarında etkili olduğu, borsa performansının, faiz oranları farklılıklarının, döviz kurunun ve ekonomik büyümenin yabancı portföy yatırımlarını pozitif yönde etkilediği şeklinde bulgulara ulaşmışlardır.

Kurt Gümüş ve Güngör (2013), çalışmalarında 2006-2012 dönemi için yabancı portföy yatırımları ile makroekonomik faktörler arasındaki ilişkiyi VAR, Var Granger Nedensellik Testleri, ve Varyans Ayrışımı kullanarak analiz etmişlerdir. Çalışma sonucunda yabancı portföy yatırımlarının İstanbul Menkul Kıymetler Borsası Fiyat Endeksi ve döviz kurlarını, sanayi üretim endeksinin de yabancı portföy yatırımlarını etkilediği belirlenmiştir.

Telek (2020), VIX korku endeksinin Türkiye'deki portföy yatırımları ve döviz kurlarına olan etkisini araştırmak için 2004:1-2019:4 dönemini üçer aylık verilerle incelemiş ve ARDL Sınır testinden yararlanmıştır. Çalışma sonucunda VIX endeksi ile döviz kurları arasında eşbütünleşme ilişkisi bulunamamış olup, VIX endeksi ile portföy yatırımları eşbütünleşme ilişkisi olduğu belirlenmiştir. Ayrıca kısa dönem katsayılarının anlamlı ve pozitif, uzun dönem katsayılarının anlamsız olduğu görülmüştür.

\section{Araştırma Modeli}

\subsection{Veri Seti ve Yöntem}

Döviz Kurunu temsilen ABD doları ve VIX endeksi ile portföy yatırımları değişskenlerinin yer aldığı çalışmada, Ocak 2009Ekim 2021 tarihleri arasındaki aylık veriler kullanılmıştır. ABD doları ve portföy yatırımı verileri TCMB EVDS'den, VIX Endeksi değerleri ise tr.investing.com adresinden elde edilmiştir.

Çalışmada nicel araştırma yöntemleri ve yapılan ekonometrik analizde E-Views-10 programı kullanılmıştır. Model oluşturulmadan önce analizde kullanılan değişkenlerin durağanlık testi için Augmented Dickey Fuller (ADF) ve Phillips Perron (PP) birim kök testi kullanılmıştır. Devamında ise eşbütünleşme ilişkisinin tespiti için ARDL Sınır testi yöntemi kullanılmıştır.

Analizde kullanılan değişkenler;

- $\quad$ - PFY: Porföy Yatırımları

- - VIX: Volatilite Endeksi

- - DK: Döviz Kuru şeklinde olup çalışmada esas alınan temel fonksiyon şu şekildedir:
Portföy Yatırımları = $\mathrm{f}($ Döviz kuru, VIX endeksi $)$

$\mathrm{Bu}$ fonksiyon (1) nolu eşitlikte verilen doğrusal bir tahmin denklemi ile şu şekilde oluşturulmuştur:

$\ln P Y=\beta_{0}+\beta_{1} \ln V I X+\beta_{2} \ln D K+\varepsilon_{i}$

doğrusal tahmin denkleminde yer alan değişkenlerin doğal logaritmaları alınarak hesaplamalar yapılmıştır. Denklemde $\beta 0$ sabit terimi, $\beta 1$ eğim katsayısını, $\varepsilon i$ ise hata terimini göstermekte olup değişkenler doğal logaritmaları hesaplamaya dahil edilmiştir.

$$
\begin{aligned}
& \ln P Y=\alpha_{0}+\sum_{\mathrm{i}=1}^{\mathrm{m}} \beta_{1} \Delta \ln \mathrm{PY}_{\mathrm{t}-\mathrm{i}}+\sum_{\mathrm{i}=0}^{\mathrm{n}} \beta_{2} \Delta \ln \mathrm{VIX}_{\mathrm{t}-\mathrm{i}}+\sum_{\mathrm{i}=0}^{\mathrm{p}} \\
& \beta_{3} \Delta \ln \mathrm{DK}_{\mathrm{t}-\mathrm{i}}+\delta 1 \Delta \ln \mathrm{PY}_{\mathrm{t}-1}+\delta 2 \Delta \ln \mathrm{VIX}_{\mathrm{t}-1}+\delta 3 \Delta
\end{aligned}
$$

$\ln \mathrm{DX}_{\mathrm{t}-1}+\varepsilon_{i}$

Yukarıdaki eşitlikte; $\alpha$ sabit terimi, $\Delta$ değişkenlerin birinci farklarını, عi hata terimini göstermektedir. Gecikme uzunluğu esas olarak Akaike Bilgi Kriterine göre belirlenmektedir. (2) nolu denklemde regresyon denklemi tahmin edildikten sonra eşbütünleşme ilişkisinin yani uzun dönemli ilişkinin olup olmadığ $\mathrm{F}$ istatistiği ile incelenmekte olup kurulan hipotezler şu şekildedir:

$H_{0}: \delta 1=\delta 2=\delta 3=0$ (Değişkenler arasında eş bütünleşme ilişkisi bulunmamaktadır.)

$H_{1}: \delta 1 \neq \delta 2 \neq \delta 3 \neq 0$ Değişkenler arasında eş bütünleşme ilişkisi bulunmaktadır.)

Sonuçta bulunan F istatistiği, Pesaran Shin ve Smith'in (2001) çalışmalarında belirtilen kritik değerlerle kıyaslanmakta, F istatistiği, söz konusu çalışmada belirtilen alt ve üst kritik değerden büyük ise $\mathrm{H}_{0}$ reddedilerek değişkenler aras1 eşbütünleşme olduğuna, alt ve üst kritik değerden küçükse $\mathrm{H}_{0}$ kabul edilerek değişkenler arasında eşbütünleşme ilişkisinin bulunmadığına karar verilmektedir. F test istatistiği değerinin kritik değerler arasında kalması halinde ise eşbütünleşmenin olup olmadığına dair bir yorum yapmak mümkün olmamaktadır.

$\mathrm{H}_{0}$ hipotezinin reddedilmesi yani eş bütünleşme ilişkisinin bulunması durumunda kısa ve uzun dönem katsayılarının tahmin edilmesi aşamasına geçilmekte, ardından tespit edilen en uygun gecikme uzunlukları kullanılarak hata düzeltme modeli tahmin edilmektedir. Uzun dönem katsayılarının tahmini için $\operatorname{ARDL}(m, n, p)$ katsayılarının tahmin edilmesi için seçilen en uygun gecikmeli modelin ARDL $(m, n, p)$ olduğu bir denklemde; " $m$ " bağımlı değişkene ait gecikme uzunluğunu; " $n$ " ve "p" ise bağımsız değişkenlere ait gecikme uzunluklarını göstermektedir. Değişkenlerin uzun dönemli ilişkisinin varlığına yönelik kurulan denklem 3'teki ARDL modeli aşağıdaki gibidir:

$$
\ln P Y=\alpha_{0}+\sum_{\mathrm{i}=1}^{\mathrm{m}} \alpha_{1 i} \ln P \mathrm{Y}_{\mathrm{t}-\mathrm{i}}+\sum_{\mathrm{i}=0}^{\mathrm{n}} \alpha_{2 i} \ln \mathrm{VIX}_{\mathrm{t}-\mathrm{i}}+\sum_{\mathrm{i}=0}^{\mathrm{p}} \alpha_{3}
$$

$\ln \mathrm{DK}_{\mathrm{t}-i}+\varepsilon_{i}$ 
Araştırmada kısa dönemli ilişkinin varlığına yönelik kurulan ARDL hata düzeltme modeli ise aşağıdaki denklem 4'teki gibidir:

$$
\begin{aligned}
& \Delta \ln P Y=\alpha_{0}+\sum_{\mathrm{i}=1}^{\mathrm{m}} \lambda_{1 i} \Delta \ln P \mathrm{Y}_{\mathrm{t}-\mathrm{i}}+\sum_{\mathrm{i}=0}^{\mathrm{n}} \lambda_{2 i} \Delta \ln \mathrm{VIX}_{\mathrm{t}-\mathrm{i}} \\
& +\sum_{\mathrm{i}=0}^{\mathrm{p}} \lambda_{3 i} \Delta \ln \mathrm{DK}_{\mathrm{t}-\mathrm{i}}+\lambda_{4 i} \mathrm{ECT}_{\mathrm{t}-\mathrm{i}}+\varepsilon_{i}
\end{aligned}
$$

Yukarıda yer alan eşitlikte $\Delta$; serilerin bir derece farkının alındığını ifade etmektedir. ECT ise hata düzeltme terimini göstermekte, uzun dönem analizinden elde edilen hata terimi serisinin bir dönem gecikmeli değeri olup, bu terimin katasayısının -1 ile 0 arasında ve istatistiksel olarak anlamlı olması beklenmektedir. Bu terimin işaretinin negatif ve istatistiki olarak anlamlı olması, uzun dönemde birlikte hareket eden seriler arasında kısa dönemde meydana gelen sapmaların ortadan kalktığını ve serilerin tekrar uzun dönem denge düzeyine yaşlaştıklarını ifade etmektedir (Tarı, 2008). Ayrıca -1'e yakın bir değer kısa dönemdeli sapmaların daha hızlı, 0'a yakın bir değer ise kısa dönemdeki sapmaların daha yavaş dengeye geldiği şeklinde yorumlanmaktadır.

\subsection{Analiz ve Bulgular}

Değişkenler arasındaki kısa ve uzun dönemli ilişkinin yorumlanmasında kullanılacak testin belirlenmesi için serilerin birim kök testlerine bakılması gerekmektedir. Birim kök testleri serilerin hangi düzeyde durağan olduklarının tespit edilebilmesi için uygulanmaktadır. Test sonuçlarından elde edilen verilere göre hangi analizin uygulanması gerektiği sonucuna varılmaktadır. $\mathrm{Bu}$ nedenle Augment Dickey Fuller (ADF) ve Phillips-Perron (PP) birim kök testleri kullanılmış ve hipotezler şu şekilde kurulmuştur:

$\mathrm{H}_{0}$ : Seride birim kök vardır, seri durağan değildir.

\begin{tabular}{|c|c|c|c|c|c|}
\hline \multirow[b]{2}{*}{ Değiş̧kenler } & \multicolumn{2}{|c|}{ ADF } & \multicolumn{2}{|c|}{ PP } & \multirow[b]{2}{*}{ Karar } \\
\hline & $\begin{array}{l}\text { Düzey (sabitli ve } \\
\text { trendli) }\end{array}$ & $\begin{array}{l}\text { 1.Fark (sabitli } \\
\text { ve trendli) }\end{array}$ & $\begin{array}{c}\text { Düzey (sabitli ve } \\
\text { trendli) }\end{array}$ & $\begin{array}{c}\text { 1.Fark (sabitli ve } \\
\text { trendli) }\end{array}$ & \\
\hline \multirow{2}{*}{ LNPY } & $0.0003^{*}$ & $0.0000^{*}$ & $0.0075^{*}$ & $0.0000^{*}$ & \multirow{2}{*}{$\mathrm{I}(0)$} \\
\hline & $(-5.0328)$ & $(-7.8578)$ & $(-4.1125)$ & $(-11.4585)$ & \\
\hline \multirow{2}{*}{ LNDK } & $0.2093^{*}$ & $0.0000^{*}$ & $0.2647^{*}$ & $0.0000^{*}$ & \multirow{2}{*}{$\mathrm{I}(1)$} \\
\hline & $(-2.7741)$ & $(-13.4356)$ & $(-2.636)$ & $(-13.3808)$ & \\
\hline \multirow{2}{*}{ LNVIX } & $0.0010^{*}$ & $0.0000^{*}$ & $0.0019^{*}$ & $0.0000^{*}$ & \multirow{2}{*}{$\mathrm{I}(0)$} \\
\hline & $(-4.7188)$ & $(-7.1548)$ & $(-4.5319)$ & $(-22.4197)$ & \\
\hline
\end{tabular}

$\mathrm{H}_{1}$ : Seride birim kök yoktur, seri durağandır.

Tablo 1. ADF ve PP Birim Kök Testi Sonuçları

Not: *\%1 anlamlılık düzeyini ifade etmektedir. Kritik değerler parantez içerisinde gösterilmiştir.

Tabloya göre ADF ve PP test sonuçları dikkate alındığında VIX korku endeksi ve portföy yatırımları değişkeninin seviyede, döviz kuru değişkeninin ise 1. farkı alındığında durağan hale geldiği görülmektedir. Hipotezlere baktığımızda, değişkenlerin farklı düzeylerde durağan olmalarına bağlı olarak EngleGranger veya Johansen Eş Bütünleşme testlerinin yapılması uygun görülmemektedir. $\mathrm{Bu}$ da $\mathrm{ARDL}$ analizinin yapılmasını gerektirmektedir. ARDL modeli farklı düzeylerde durağan çıkan seriler için kullanılabildiğinden, bu çalışmada ARDL modelinin kullanılmasının daha anlamlı sonuçlar vereceği düşünülmektedir.

ARDL modelinin oluşturlabilmsi için öncelikle gecikme uzunluğunun belirlenmesi gerekmektedir. Model için uygun olan gecikme uzunluğu sayısının belirlenmesi için Akaike, Scharz ve Hannan-Quinn gibi kritik değerler kullanılarak en küçük kritik değeri veren gecikme uzunluğu modelin gecikme uzunluğu olarak seçilmektedir. Dolayısıyla bu çalışmada optimal gecikme uzunluğu belirlenirken AIC tercih edilmiştir. Bu kritere göre seçilen en küçük değeri veren 20 model olup en uygun ARDL modelinin gecikme uzunluğu ARDL $(1,1,0)$ olarak hesaplanmıştır.

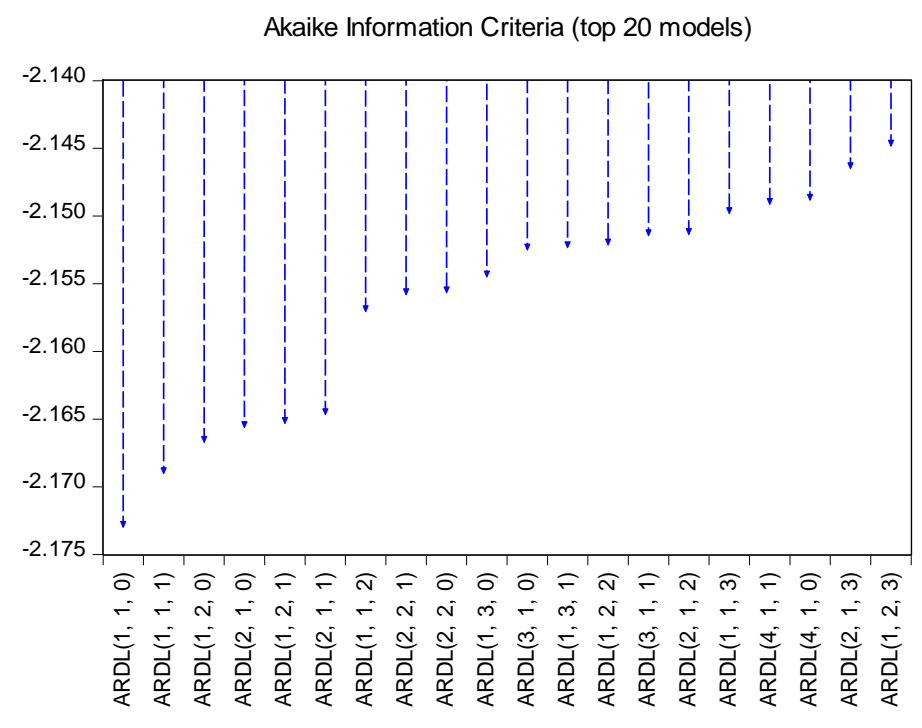

Şekil 1 : Uygun Model Seçimi

$\mathrm{Bu}$ kapsamda, gerçekleştirilen analizlerde bu model temel alınmış ve aşağıdaki tabloda tercih edilen ARDL $(1,1,0)$ modeline ilişkin sınır testi sonuçları Tablo 2'de raporlanmıştır. 
Tablo 2. ARDL $(1,1,0)$ Sinır Testi Sonuçları

\begin{tabular}{|c|c|c|c|c|}
\hline $\mathbf{k}$ & F istatistiği & Önem Düzeyi & Alt Sınır & Üst Sınır \\
\hline \multirow{3}{*}{2} & \multirow{3}{*}{$7.918911^{* * *}$} & $\% 10$ & 3.38 & 4.02 \\
\cline { 2 - 5 } & & $\% 5$ & 3.88 & 4.61 \\
\cline { 2 - 5 } & & $\% 1$ & 4.99 & 5.85 \\
\hline
\end{tabular}

Not: Maksimum gecikme uzunluğu 4 olarak alınmıştır. k, açıklayıcı değişken sayısını ve *** ise \%1 düzeyinde anlamlılığ

Tablo 2'de görüldüğü gibi, ARDL $(1,1,0)$ modeli için hesaplanan $\mathrm{F}$ istatistiği değerinin \%1 anlamlılık düzeyinde kritik değerlerden büyük olması nedeniyle değişkenler arasında eşbütünleşme ilişkisi bulunmadığına yönelik kurulan $\mathrm{H}_{0}$ hipotezi reddedilerek, değişkenler arası eşbütünleşme ilişkisi olduğu tespit edilmiştir. Uzun dönemli eşbütünleşme ilişkisi tespit edildikten sonra değişkenlere ait uzun ve kısa dönem ilişkilerin incelenmesi gerekmektedir. ARDL $(1,1,0)$ modeline ait uzun ve kısa dönem katsayıları Tablo 3 'te gösterilmiştir.

Tablo 3. ARDL $(1,1,0)$ Modeli Kısa ve Uzun Dönem İlişkiler

\begin{tabular}{|}
\begin{tabular}{|c|c|c|c|c|}
\hline Uzun Dönem Katsayıları (Bağımlı değişken: LNPY) \\
\hline Değişkenler & Katsayı & Standart Sapma & t-istatistiği & Olasıllk \\
\hline LNDK & -0.0006 & 0.639109 & -1.440008 & 0.0000 \\
\hline LNVIX & 0.135120 & 0.110000 & -4.664722 & 0.7290 \\
\hline @TREND & -0.006095 & 0.001405 & -4.337266 & 0.0000 \\
\hline Kısa Dönem Katsayıları (Hata Düzeltme Modeli) & 0.311897 & -4.403998 & 0.0000 \\
\hline$\Delta$ LNDK & -0.0291369 & 0.332187 & 6.832155 & 0.0000 \\
\hline$\Delta$ LNVIX & 1.102981 & 0.031861 & -5.685252 & 0.0000 \\
\hline CointEq(-1)* & -0.621139 & &
\end{tabular} \\
\hline
\end{tabular}

Tablo 3'e göre, DK ve VIX değişkenlerinin uzun dönem katsayıları sırasıyla -0.0006 ve 0.13 olup yalnızca döviz kuru değişkeninin \%1 önem düzeyinde anlamlı çıktığı tespit edilmiştir. Bu durum döviz kurunda oluşabilecek \%1'lik bir artışın portföy yatırımlarını uzun dönemde yaklaşık \%0.06 oranında azaltacağı anlamına gelmektedir.

Kısa dönem katsayı sonuçlarına incelendiğinde ise döviz kuru ile portföy yatırımları arasında negatif, VIX korku endeksi ile portföy yatırımları arasında ise pozitif ve anlamlı bir etki olduğu görülmektedir. Yani VIX endeksinde oluşabilecek \%1'lik bir artış portföy yatırımlarını yaklaşık \% 1.10 oranında artırırken; döviz kurunda oluşabilecek \%1'lik bir artış ise portföy yatırımlarını $\% 2.9$ oranında azaltmaktadır.

Tablo 4. ARDL $(1,1,0)$ Modeli için Tanısal Test Sonuçlart
Değişkenler arasındaki kısa dönemli ilişkiyi incelemek amaciyla tahmin edilen ARDL Hata Düzeltme Modeli sonuçlarına bakıldığında ise uzun dönem ilişkisinden elde edilen hata terimleri serisinin bir dönem gecikmeli değerini gösteren hata düzeltme katsayısının (ECT-1), negatif işaretli ve istatistiksel olarak anlamlı çıktığı görülmektedir. Bu durum kısa dönemde meydana gelen sapmaların uzun dönemde dengeye yaklaşacağı anlamına gelmektedir. Yani kısa dönemdeki bir sapmanın \%62'si, bir sonraki dönemde düzeltilmektedir.

\begin{tabular}{|l|l|}
\hline Tanısal Testler & İstatistikler \\
\hline $\mathrm{R}^{2}$ & 0.946 \\
\hline Düzeltilmiş $\mathrm{R}^{2}$ & 0.944 \\
\hline F istatistiği & $515.68 \quad(0.000)$ \\
\hline Otokorelasyon (LM) & $0.320 \quad(0.726)$ \\
\hline Değişen Varyans & $1.55 \quad(0.176)$ \\
\hline Ramsey Reset Testi & $0.523 \quad(0.639)$ \\
\hline
\end{tabular}

Not: Parantez içindeki rakamlar olasılık değerlerini göstermektedir. 
Tablo 4'te ARDL $(1,1,0)$ modeli için hesaplanan tanısal test sonuçlarına yer verilmiştir. Buna göre $\mathrm{R}^{2}(0.946)$ ve düzeltilmiş $\mathrm{R}^{2}$ (0.944) olasılık değeri; bağımlı değişkenin bağımsız değişkenler tarafından açıklanma oranını, F istatistiği olasılık değeri (0.000); modelin bir bütün olarak anlamlı olduğunu, otokorelasyon LM test olasılık değeri $(0.726)$; modelin hata terimlerinde otokorelasyon mevcut olmadığını, değişen varyans Breusch-Pagan-Godfrey test olasılık değeri $(0,176)$; modelde hata terimlerinde değişen varyans olmadığını (sabit olduğunu) ve Ramsey Reset Test olasılık değeri $(0,639)$ ise modelde model kurma hatasının olmadığını göstermektedir. Tahmin edilen uzun dönem katsayılarının istikrarlı olup olmadı̆̆ı ve yapısal kırılmanın olup olmadığını belirlemek için CUSUM ve CUSUM-Q testleri ile belirlenebilmektedir.
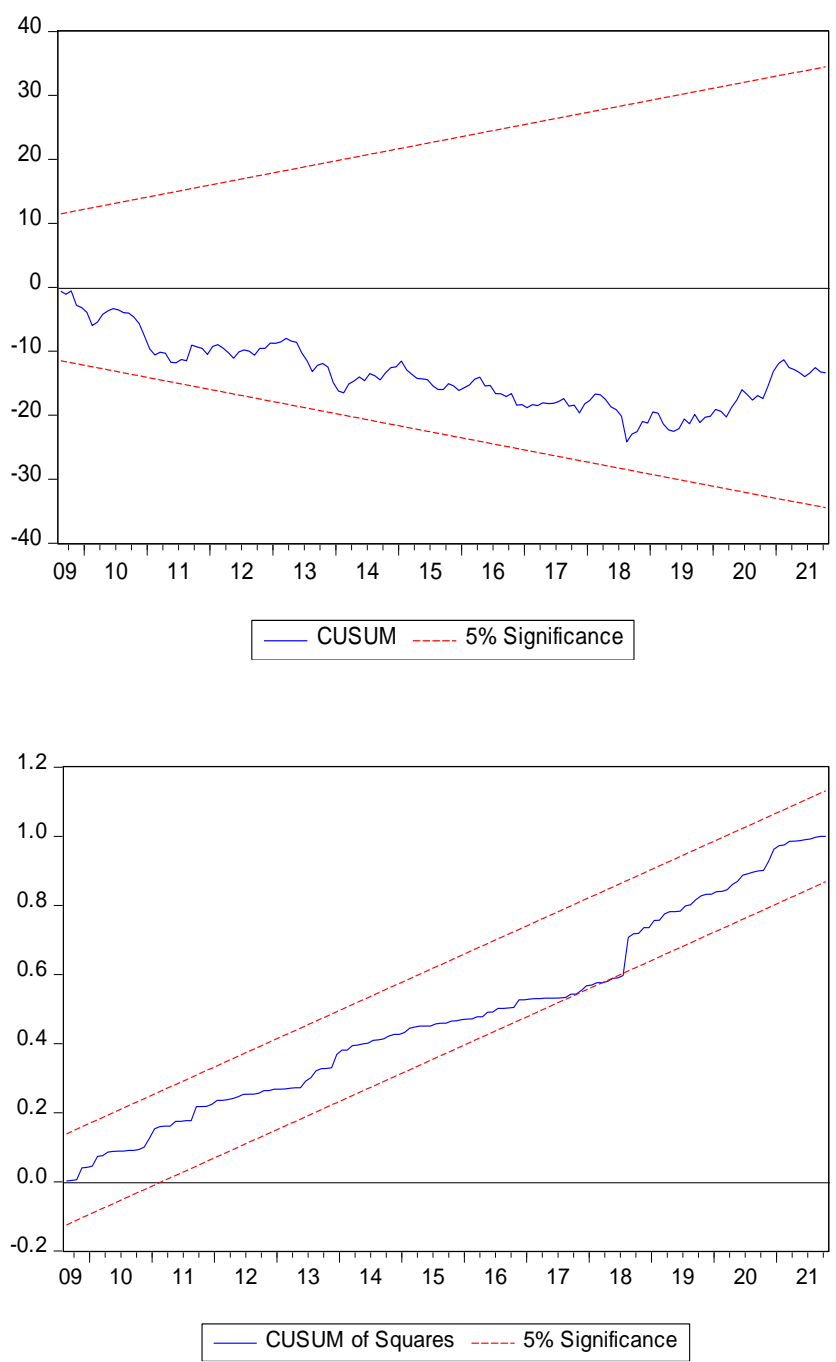

\section{Şekil 2: CUSUM Testi Sonuçları}

CUSUM ve CUSUMSQ istatistiklerinde tekrar eden kalıntı değerlerinin kümülatif toplamı \% 5 önem düzeyinde kritik sınırlar içerisinde (iki sınır içerisinde) yer alması durumunda ARDL modelindeki katsayıların istikrarlı ve modelin güvenilir olduğu anlaşılmaktadır. Dolayısıyla katsayıların istikrarlı ve modelin güvenilir olduğu olduğunu ifade eden $\mathrm{H}_{0}$ hipotezi kabul edilecektir (Bahmani-Oskooee, Ng, 2002: 25). CUSUM grafikleri sınırların dışında yer alırsa katsayıların durağanlığını savunan $\mathrm{H}_{0}$ hipotezinin reddedilmesi gerekecektir. Dolayısıyla Şekil 1'deki CUSUM ve CUSUMSQ grafikleri incelendiğinde, değişkenlere ait herhangi bir yapısal kırılmanın olmadığını, ARDL Sınır Testine göre hesaplanan uzun dönem katsayıların istikrarlı olduğunu ve kırılmayı ifade etmek üzere herhangi bir yapay değişken kullanmadan modelin tahmin edilebileceğini söylemek mümkündür.

\section{Sonuç ve Öneriler}

Finansal piyasaların son yıllarda oldukça gelişmesi ve karmaşık bir hal alması sonucu yatırımcıların risk algısı da artmakta ve sürekli gelişen bu ortamda risk seviyelerini azaltmak istemektedirler. Uluslararası yatırımlar kapsamında ise yabancı portföy yatırımcıları döviz kuru riski de dahil olmak üzere çeşitli riskler üstlenerek getiriler sağlamayı amaçlamaktadırlar. Bununla birlikte yatırım kararı alırken ülkedeki istikrar ile ekonomik politikaların tutarlılık ve sürekliliğine göre hareket etmektedirler. Bu noktada yatırımcılar için yüksek getiri sağlamak ve risklerden kaçınabilmek adına belirsizlik ölçütünün göstergesi olan VIX korku endeksi yol gösterici olmaktadır. Ayrıca yabancı yatırımcılar için VIX korku endeksinin yanı sıra istikrarlı bir döviz kuru da belirleyici olmaktadır (Sezer, 2020: 838). Dolayısıyla ulusal reel kurdaki oynaklıklar da ülke ekonomilerinin rekabet gücünün yanı sıra dış ticaret yapısını ve yatırımcı kararlarına bağlı olarak yabancı sermaye akımlarını da doğrudan etkilemektedir.

Bu bağlamda çalışmada, Portföy Yatırımları (PY) ile Döviz Kuru (DK) ve VIX korku endeksi arasında kısa ve uzun dönemli denge ilişkilerinin varlığı ARDL Sınır Testi yaklaşımı kullanılarak belirlenmeye çalışılmıştır. Ocak 2009 - Ekim 2021 tarihleri arasındaki aylık veriler kullanılarak gerçekleştirilen ARDL Sınır Testi sonuçlarına göre portföy yatırımları, döviz kuru ve VIX korku endeksi arasında uzun dönemli bir ilişki bulunmakla birlikte, modellerdeki uzun dönem katsayı tahmin sonuçlarına bakıldığında yalnızca döviz kurunun portföy yatırımları üzerinde anlamlı bir etkiye sahip olduğu anlaşılmıştır. Hata düzeltme modeli sonuçlarına göre ise kısa dönemde döviz kurunun portföy yatırımları üzerinde negatif ve anlamlı, VIX değişkeninin ise portföy yatırımları üzerinde pozitif ve anlamlı bir etkisinin olduğu görülmektedir. Dolayısıyla çalışmadan elde edilen sonuçlar Telek'in (2020) çalışma sonuçlarıyla uyumluluk göstermektedir. Hata düzeltme katsayısının tahmin değeri sonucu ise -0.621 olup kısa dönem şoklarını takiben uzun dönem dengesinden meydana gelecek sapmaların 1 dönem sonrasında $\% 62$ 'sinin giderilebildiğini göstermektedir.

$\mathrm{Bu}$ sonuçlar hem politika yapıcılar hem de yatırımcılar açsısından VIX endeksinde meydana gelecek dalgalanmaların önemini ve VIX endeksinde meydana gelecek bir değişikliğin kısa dönemde Türkiye'ye yapılan portföy yatırımları üzerinde etkili olduğunu göstermektedir.

\section{Kaynakça}

Afşar, M. (2004). Doğrudan Yabancı Yatırımlar ve Bankacılık Sektörü. Ege Akademik Bakış, 4 (1), 85-101.

Agarwal, R. N. (1997). Foreign Portfolio Investment In Some Developing Countries: A Study of Determinants and Macroeconomic Impact. Indian Economic Review. 32(2), 217-229.

Agu, Anthony Ogbonna, Ogu Calistus, Ezeanyeji Clement (2019). Foreign Portfolio Investment and Stock Market Returns in Nigeria. Journal of Economics and Finance, 10 (6), 1-9. 
Akdağ, S. (2019). Effect of VIX Fear Index on Financial Indicators: Turkey Case, Hitit University Journal of Social Sciences Institute, 12(1), 235-256.

Aktaş, C. (2010). Türkiye'de Reel Döviz Kuru ile İhracat ve İhracat Arasındaki İlişkinin VAR Tekniğiyle Analizi. Zonguldak Karaelmas Üniversitesi Sosyal Bilimler Dergisi, 6 (11), 123-140.

Arbatli E. (2011). Economics Policies and FDI Inflows to Emerging Market Economies. IMF Working Paper, 11/192.

Bagchi, D. (2012). Cross-Sectional Analysis of Emerging Market Volatility Index (India VIX) With Portfolio Returns. International Journal of Emerging Markets, 7(4), 383-396.

Basher, S. A. ve Sadorsky, P. (2016). Hedging Emerging Market Stock Prices With Oil, Gold, VIX, and Bonds: A Comparison Between DCC, ADCC and GOGARCH. Energy Economics, 54, 235-247.

Bektaş, N. Ç. ve Babuşcu, Ş. (2019). VIX Korku Endeksi ve Cds Primlerinin Büyüme ve Döviz Kuruna Etkisi, Türkiye Örneği. Ufuk Üniversitesi Sosyal Bilimler Enstitüsü Dergisi, 8(16), 97-111.

Çağlar Bektaş, N. ve Babuşcu, Ş. (2019). VIXX Korku Endeksi v e CDS Primlerinin Büyüme ve Döviz Kuruna Etkisi, Türkiy e Örneği . Ufuk Üniversitesi Sosyal Bilimler Enstitüsü Dergi si , 8 (16), 97-111.

Edwards, S., Enders, T. O. ve Silva-Herzog, J. (1988). The United States and Foreign Competition in Latin America. In The United States in the World Economy (pp. 9-77). University of Chicago Press.

Egly, P. V., Johnk, D. W. ve Liston, D. P. (2010). Foreign Portfolio Investment Inflows to the United States: The Impact of Investor Risk Aversion and US Stock Market Performance. Norh American Journal of Finance and Banking Research. 4(4), 25-41.

Elekwa, P., Aniebo, C., and Ogu, C. (2016). Does foreign portfolio investment affect employment growth in Nigeria. Journal of Economics and Sustainable Development, 7(12), 81-84.

Emna, R., ve Myriam, C. (2017). Dynamics of The Relationship Between Implied Volatility Indices and Stock Prices Indices: The Case of European stock markets. Asian Economic and Financial Review, 7(1), 52-62.

Ercan, S. ve Demirbaş, B. (2021). Abd Dolar Endeksi İle V1x Korku Endeksi Arasındaki İlişki: Ardl Sınır Testi Yaklaşımı. Bilgi Ekonomisi ve Yönetimi Dergisi, 15(2), 115129.

Garg, R. ve Dua, P. (2014). Foreign Portfolio Investment Flows to India: Determinants and Analysis, World Development. $59,16-28$.
Gülhan Ü. (2020). Altın Fiyatları İle VIXX endeksi, BİST 100 En deksi, Döviz Kuru ve Petrol Fiyatları Ilişkisi: Ekonometrik Bir Analiz. Gümüşhane Üniversitesi Sosyal Bilimler Enstitüs ü Elektronik Dergisi, 11 (2), 576-591.

Gümüş, G. K., Duru, A. ve Güngör, B. (2013). The Relationship Between Foreign Portfolio Investment and Macroeconomic Variables. European Scientific Journal, 9 (34). 209-226.

Kaya, A. ve T. Öndeş. (1997). Türkiye'de Yabancı Portföy Yatırımlarının Belirleyicileri. IMKB Dergisi, 13 (52), 19-38.

Kaya, A., Güngör, B. ve Özçomak, M. S. (2014). Is VIX Indeks a Fear Indeks for Investors? OECD Countries Stock Exchange Example with ARDL Approach. Proceedings of the First Middle East Conference on Global Business, Economics, Finance and Banking (ME14 DUBAI Conference) Dubai, 10-12 October 2014.

Kiracı, K. (2019). BİST Turizm Endeksi İle Dolar Kuru, Dolar Endeksi ve Petrol Fiyatları Arasındaki Nedensellik Ilişkisinin Ampirik Analizi. Erciyes Üniversitesi İktisadi ve İdari Bilimler Fakültesi Dergisi, (53), 73-86.

Kliger, D. ve Kudryavtsev A. (2013). Volatility Expectations and The Reaction To Analyst Recommendations. Journal of Economic Psychology, 2013, 3 (C), 1-6.

Kodongo, O. ve Ojah, K. (2012). The Dynamic Relation Between Foreign Exchange Rates and International Portfolio Flows: Evidence from Africa's Capital Markets. International Review of Economics and Finance. Say1 24.

Kök, D. ve Nazlığlu, E. H. (2020). Finansal Piyasalarda Asimetrik Nedensellik: BIST100, VIX ve Döviz Kuru Örneği . Erciyes Üniversitesi İktisadi ve İdari Bilimler Fakültesi Dergisi, (55), 245-262.

Mann. C. L. (2002). Perspectives on the U.S. Current Account Deficit and Sustainability. Journal of Economic Perspectives, 16 (3), 131-152.

Münyas, T. ve Bektur, Ç. (2021). Korku Endeksi (VIX) ile Kredi Temerrüt Swap (CDS), Dolar Kuru, Euro Kuru, BİST 100 ve Altın Arasındaki İlişkinin Değerlendirilmesi: Türkiye Örneği . TESAM Akademi Dergisi , 8 (2), 555-571.

Neffelli, M. ve Resta, M. (2018). Is VIX Still The Investor Fear Gauge? Evidence For The US and BRIC Markets. Arxiv Preprint Arxiv: 1806.07556.

Oskooee, M. B. ve Sohrabian, A. (1992). Stock Prices And The Effective Exchange Rate of the Dollar. Applied Economics, 24(4), 459-464

Öner, H., Şarkaya İçellioğlu, C. ve Öner, S. (2018). Volatilite Endeksi (VIX) ile Gelişmekte Olan Ülke Hisse Senedi Piyasası Endeksleri Arasındaki Engel-Granger EşBütünleşme ve Granger Nedensellik Analizi. Finansal Araştırmalar ve Çalışmalar Dergisi, 10(18), 110-124. 
Pal, P. (2011). Foreign Portfolio Investment, Stock Market and Economic Development: A Case Study of India. Capital Without Borders: Challenges to Development, 1, 121.

Pazarlığlu, M. V. ve E. Gülay. (2007). Net Portföy Yatırımları ile Reel Faiz Arasındaki İlişki ve Türkiye Örneği-1992: I2005: IV. Dokuz Eylül Üniversitesi Sosyal Bilimler Enstitüsü Dergisi, 9 (2), 201-221.

Sadeghzadeh, K. (2018). Borsanin Psikolojik Faktörlere Duyarliliği: Oynaklik Endeksi (VIX) ve Tüketici Güven Endeksi (TGE) İle Bist 100 Endeksi Arasindaki İlişkiler. Cumhuriyet Üniversitesi İktisadi ve İdari Bilimler Dergisi, 19(2), 238-253.

Sarıtaş, H. ve Nazlığlu, E. H. (2019). Korku Endeksi, Hisse Senedi Piyasası ve Döviz Kuru İlişkisi: Türkiye İçin Ampirik Bir Analiz . Ömer Halisdemir Üniversitesi İktisadi ve İdari Bilimler Fakültesi Dergisi, 12 (4), 542-551.

Tarı, R. (2008). Ekonometri, Kocaeli: Kocaeli Üniversitesi Yayınevi

Telçeken, N., Kıyılar, M. ve Kadığlu, E. (2019). Volatilite endeksleri: Gelişimi, Türleri, Uygulamaları ve TRVIX Önerisi. Ekonomi Politika ve Finans Araştırmalarl Dergisi, 4(2), 204-228.

Telek, C. (2020). VIX Endeksinin Türkiye'de Portföy Yatırımları ve Döviz Kurlarıyla İlişsisi. İzmir İktisat Dergisi, 35(3), 635-646.

Tezer, H. (2020). Uluslararası Sermaye Hareketlerinin Türkiye Ekonomisi Üzerindeki Makroekonomik Etkisinin İncelenmesi (2008-2018). Atatürk Üniversitesi Sosyal Bilimler Enstitüsü Dergisi, 24(2), 831-859. 